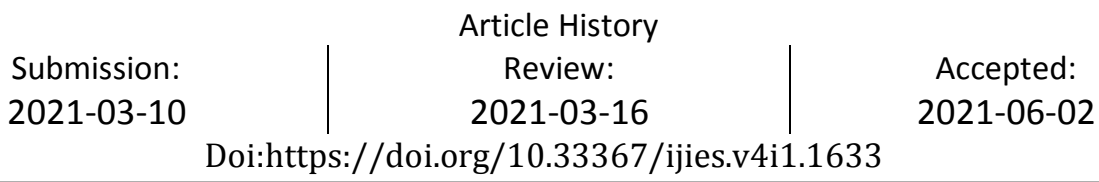

\title{
Internalisasi Nilai Multikulturalisme melalui Pendidikan Islam; Interelasi Tri Sentra Pendidikan pada Masyarakat Multireligius Desa Balun Lamongan
}

\author{
Ahmad Hanif Fahruddin ${ }^{1}$, Maskuri ${ }^{2}$, Hasan Busri ${ }^{3}$ \\ ${ }^{1}$ Universitas Islam Lamongan, ${ }^{2,3}$ Universitas Islam Malang \\ ${ }^{1}$ kanghanif88@unisla.ac.id, ${ }^{2}$ masykuri@unisma.ac.id, ${ }^{3}$ hasanbusri@unisma.ac.id
}

\begin{abstract}
Balun Village community located in Turi Subdistrict, Lamongan Regency got predicate as Pancasila village. This social attribute is inherent not only because its inhabitants have theological diversity as a multi religious society, but because of their success in managing religious diversity into a harmonious and almost conflictless social order. This success story is behind this research, which aims to parse about the role of various parties in shaping the multicultural society order. This study uses qualitative method with phenomenological approach. This study successfully found, among others: 1) multiculturalism successfully internalized through various parties integrativedialectical, both in the family environment, school and community, 2) internalized multicultural values include tolerance (tasamuh), social harmony (tawazun), mutual help (ta'awun) and moderation in religion (tawasuth),3) the process of internalization of multicultural values is carried out through two patterns both additively and transformative level. In addition, this study also found that the internalization of multicultural values goes through the stages of value transformation, value transactions and trans-internalization of values embodied through the teaching and culture of society with a tolerant attitude (tasamuh)as well as moderate( tawasuth).
\end{abstract}

Keywords: Internalitation, Islamic Education, Multiculturalism

\begin{abstract}
Abstrak
Masyarakat Desa Balun yang terletak di Kecamatan Turi, Kabupaten Lamongan mendapat predikat sebagai desa Pancasila. Atribut sosial ini melekat bukan hanya karena penduduknya memiliki diversitas teologis sebagai masyarakat multireligius, namun karena keberhasilan mereka dalam mengelola keberagaman agama menjadi satu tatanan sosial yang harmonis dan nyaris tanpa konflik. Cerita sukses inilah yang melatarbelakangi penelitian ini, yaitu bertujuan untuk mengurai tentang peran berbagai pihak dalam membentuk tatanan masyarakat multikultural. Penelitian ini menggunakan metode kualitatif dengan pendekatan fenomenologi. Kajian ini berhasil menemukan, antara lain: 1) multikulturalisme berhasil diinternalisasikan melalui hubungan interrelasi berbagai pihak secara integratif-dialektif, baik di lingkungan keluarga, sekolah dan masyarakat, 2) nilai-nilai multikultural yang diinternalisasikan meliputi sikap toleransi (tasamuh), harmoni sosial (tawazun), saling tolong-menolong (ta'awun) dan
\end{abstract}


moderasi dalam beragama (tawasuth), 3) proses internalisasi nilai-nilai multikultural dilakukan melalui konstribusi tri relasi pendidikan yang mengambil dua pola baik secara additive maupun transformatif level. Selain itu, penelitian ini juga menemukan bahwa internalisasi nilai multikultural berjalan melalui tahapan transformasi nilai, transaksi nilai dan transinternalisasi nilai yang diwujudkan melalui pengajaran dan pembudayaan masyarakat dengan sikap toleran (tasamuh) sekaligus moderat (tawasuth).

Kata Kunci: Internalisasi, Multikulturalisme, Pendidikan Islam

\section{Pendahuluan}

Indonesia merupakan bangsa yang memiliki keunikan dan coraknya yang khas. Menurut Clifford Geertz, sebagaimana dikutip oleh Iqbal, bahwa Indonesia merupakan negeri hibrida, karena menjadi tempat bermuaranya berbagai kultur dunia yang berhasil masuk ke Nusantara, yaitu kebudayaan Cina, Timur Tengah, India dan Eropa. ${ }^{1}$ Maka menjadi hal yang masuk akal jika di Jakarta dan Surabaya tidak sulit ditemukan pemukiman Cina dan komunitas Arab, di Bali agama Hindu yang dibawa dari India menjadi mayoritas, serta pusat peradaban Islam banyak terlacak di kawasan Aceh, Makasar dan Makasar. Di Ambon, Tomohon dan Flores simpul-simpul agama Katolik menjadi peradaban masyarakat setempat. ${ }^{2}$

Menarik untuk juga mengutip pandangan Nurcholish Madjid yang mendefinisikan bahwa kebudayaan Indonesia adalah buah dari interaksi peradaban yang kaya, dinamis dan berkesinambungan dalam satu melting pot yang efektif. Maka tak heran jika Indonesia mendapat julukan sebagagi "mega cultural diversity" disebabkan eksistensinya memuat keanekaragaman yang supra kompleks. Tak kurang dari 250 kelompok rasial lengkap dengan 500 jenis ragam bahasa berbeda di setiap etnisnya menjadikan Indonesia sebenarnya menjadi negara yang digdaya dalam konteks kebudayaan. ${ }^{3}$

Namun, kekayaan Indonesia di bidang sosio-kultural di atas, jika tidak dikelola dengan baik, akan menjadi bom waktu yang setiap saat dapat meluapkan energi konflik yang luar biasa. Hal ini karena terdapat kerentanan sosial yang jamak dihadapi oleh masyarakat multikultural, yakni: 1) menyimpan potensi perpecahan antar kelompok yang akut; 2) pihak yang bertikai cenderung melihat perpecahan sebagai sebuah

\footnotetext{
${ }^{1}$ Mahathir Muhammad Iqbal, "Pendidikan Multikultural Interreligius: Upaya Menyemai Perdamaian Dalam Heterogenitas Agama Perpsektif Indonesia," Sosio Didaktika 1, no. 1 (2014): 89-97.

${ }^{2}$ Aulia Kamal, "Spiritual-Humanisme Hasan Askari Dan Dialog Interreligi Di Indonesia," Studia Sosia Religia 2, no. 2 (2019), 28.

${ }^{3}$ J.B Banawiratma et al., Dialog Antarumat Beragama: Gagasan Dan Praktik Di Indonesia (Jakarta: PT Mizan Publika, 2010), 129.
} 
“perang” dan; 3) proses integrasi sosial cenderung bersifat hegemonik, antara kelompok satu di atas kelompok yang lain. ${ }^{4}$

Masyarakat multikultural yang menyimpan kerentanan konflik ini pada akhirnya menjadi sesuatu yang niscaya bahwa dalam sejarahnya jamak membayar mahal konflik dengan pertaruhan nyawa dan pertikaian antar sesama saudara sebangsa. Bahkan lebih parah lagi, konflik yang dimobilisasi dengan isu agama yang pernah terjadi di beberapa kawasan daerah di Indonesia, tak jarang mengorbankan jiwa hanya karena tersinggung sentimen rasialnya. Karena itulah, tantangan terberat bagi Indonesia adalah menyemai keragaman sebaik mungkin agar tidak pecah perang saudara yang sewaktu-waktu bisa pecah. Karena jika ini terjadi, maka bukan hal yang mustahil kepentingan internasional akan mengintervensi kedaulatan Indonesia.

Salah satu daerah yang memiliki kekayaan budaya dan agama adalah Desa Balun yang terletak di Kecamatan Turi, Kabupaten Lamongan. Desa ini banyak menjadi subjek riset karena iklim religius dan kohesi sosialnya yang baik. Sebagai masyarakat multireligius, Balun menyimpan berbagai fenomena yang penting untuk diungkapkan, terutama pengalamannya dalam mengelola keberagaman agama menjadi lebih produktif. Kusairi yang menjadi kepada desa di Balun mengungkapkan bahwa kesadaran masyarakat Balun akan toleransi, saling membantu, gotong royong, menghormati ritual agama masing-masing sudah terbangun lama. Dalam konteks ini, ia menyatakan: "kesadaran tersebut terjadi atas konstribusi pendidikan di keluarga, pola pendidikan di sekolah, dan tradisi di masyarakat."

Dalam pendidikan di keluarga, masyarakat Balun sudah membiasakan memberikan contoh tentang toleransi bahkan ada dalam kepala Keluarga (KK) yang dalam satu keluarga berbeda agama, mereka hidup rukun. Pendidikan keluarga terbukti mampu menumbuhkan sikap terbuka dan menghargai anak pada anak lain ini diakui oleh para pendidik, baik di lembaga pendidikan formal maupun nonformal yang ada di Desa Balun. Salah satu guru SDN I Balun Khoirul Umam mengatakan bahwa peserta didik sudah terbiasa bergaul dan berteman dengan peserta didik lain yang berbeda keyakinan dan agama, mereka tidak merasa risih dan canggung untuk bermain dan berinteraksi. Hal ini bisa terwujud karena peserta didik melihat langsung apa yang dilakukan oleh orang tua mereka saat berinteraksi dan bergaul dengan teman-teman dan tetangga yang berbeda agama.

${ }^{4}$ Muryana, "Dialog Interreligius-Kultural dan Civil Religion (Studi Atas Paguyuban Ngesti Tunggal (Pangestu),” ESENSIA XIV, no. 2 (2013): 203-2016. 
Selain keluarga, pemuka agama dan tokoh masyarakat juga mempunyai peran penting dalam menanamkan nilai-nilai multikultural dalam membangun masyarakat harmonis. Hal ini diungkapkan oleh Kusairi bahwa tokoh agama memiliki konstribusi besar dalam membangun kerukunan antar umat beragama di daerahnya. Untuk mendukung keharmonisan masyarakat, bahkan Perangkat Desa didesain memenuhi unsur representatif dari masing-masing agama. Bahkan pada momen tertentu, jika dihadapkan pada konflik atau permasalahan di Desa, seringkali diselesaikan dengan jalan dialogis, demokratis, dan kompromis yang mengedepankan asas sama-sama tidak ada yang dirugikan dari segi agama apapun. Pengalaman pengelolaan keberagaman di desa Balun, dengan demikian sangat dipengaruhi oleh peran penting tokoh agama dan masyarakat dalam menyelesaikan akar konflik yang terjadi.

Hidup harmonis dan damai juga diwujudkan dalam interaksi akademik di dalam ruang pendidikan dan pembelajaran. Untuk diketahui, di Desa Balun, internalisasi nilainilai multikulturalisme juga berjalan melalui institusi pendidikan. Di desa ini, terdapat Taman Kanak-Kanan dan Sekolah Dasar yang masing-masing memiliki peran strategis dalam memupuk spirit toleransi antar umat beragama. Institusi pendidkan formal di desa ini antara lain, TK Jamhar dan TK Pembangunan, terdapat pula dua SD Negeri, yaitu SDN I dan II Balun, serta MI Tarbiyatus Sibyan. Diversitas keagamaan, di lingkup pendidikan terakomodasi antara lain di TK Pembangunan serta SDN I dan II Balun yang terdiri dari siswa muslim, nasrani, dan Hindu. Sementara itu, di TKM Jamhar dan MI Tarbiyatus Sibyan hanya diperuntukkan oleh siswa muslim.

Sebagaimana gambaran fenomena di lapangan melalui observasi peneliti didapatkan bahwa lembaga pendidikan terlihat sangat akomodatif sehingga peserta didik yang memiliki perbedaan agama tetap dikondisikan untuk rukun, dengan pola pengajaran yang semaksimal mungkin melibatkan siswa berbeda agama menjadi satu kelompok belajar. Melalui proses pembelajaran, lembaga pendidikan tersebut melalui pendidiknya memfasilitasi komunikasi dan interaksi antar peserta didik yang berlainan agama untuk bisa hidup rukun. Hal ini dilakukan di dalam kelas maupun luar kelas. Dalam menumbuhkan keharmonisan dan saling mengenal para pendidik juga tidak memberikan tugas kelompok kepada peserta didik berdasarkan agama tertentu, akan tetapi berdasarkan topik dan materi yang diajarkan. ${ }^{5}$

${ }^{5}$ SDN 1 Balun Turi Lamongan, Observasi, Baluln, 03 Februari 2019 
Komunikasi yang baik dan pergaulan yang rukun ini terjalin karena antara guru dan siswa, serta antar siswa yang lain tidak ada yang menyinggung, mengejek, dan menghina agama dan keyakinan pendidik serta peserta didik yang berbeda agama dan keyakinan. Tidak ditemukan diskriminasi atau intoleransi dalam komunikasi dan interaksi yang berlangsung dalam lingkungan sekolah bahkan para pendidik dan peserta didik berusaha untuk saling menghormati perbedaan serta menghargai keyakinan di antara mereka sebagaimana tampak pada tabel berikut:

\begin{tabular}{|c|c|c|c|c|}
\hline No. & Tema & Keluarga & Masyarakat & Sekolah \\
\hline 1 & $\begin{array}{l}\text { Toleransi } \\
\text { (tasamuh) }\end{array}$ & $\begin{array}{l}\text { Keteladanan orang tua } \\
\text { dalam menghormati } \\
\text { yang lain }\end{array}$ & $\begin{array}{l}\text { Umat Islam } \\
\text { mematikan speaker } \\
\text { saat adzan ketika hari } \\
\text { raya Nyepi }\end{array}$ & $\begin{array}{l}\text { Tidak membagi tugas } \\
\text { berdasarkan agama } \\
\text { tertentu }\end{array}$ \\
\hline 2 & $\begin{array}{l}\text { Moderat } \\
\text { (tawasuth) }\end{array}$ & $\begin{array}{l}\text { Tidak memaksakan } \\
\text { kehendak anak }\end{array}$ & $\begin{array}{ll}\text { Tidak } & \text { saling } \\
\text { mengganggu } & \text { dalam } \\
\text { beribadah } & \end{array}$ & $\begin{array}{l}\text { Tidak menyinggung, } \\
\text { menjelekkan } \\
\text { keyakinan siswa } \\
\text { agama lain }\end{array}$ \\
\hline 3 & $\begin{array}{l}\text { Tolong- } \\
\text { Menolong } \\
\text { (ta'awun) }\end{array}$ & $\begin{array}{l}\text { Dalam satu keluarga } \\
\text { berbeda agama tidak } \\
\text { memaksakan } \\
\text { keyakinannya }\end{array}$ & $\begin{array}{ll}\text { Saling } & \text { tolong } \\
\text { menolong } & \text { dalam } \\
\text { kegiatan perayaan }\end{array}$ & $\begin{array}{lr}\text { Memfasilitasi } & \text { untuk } \\
\text { komunikasi } & \text { dan } \\
\text { interaksi } & \end{array}$ \\
\hline
\end{tabular}

Tabel: Multikulturalisme dalam Tri Centra Pendidikan

\section{Metode}

Kajian ini dilakukan dengan menggunakan jenis penelitian kualitatif dengan studi lapangan (field research). ${ }^{6}$ Data diperoleh dari wawancara dengan informan kunci (key informan), observasi langsung serta dokumentasi. Hasil dari inventarisasi data kemudian dianalisis dengan menggunakan model analisis Miles \& Huberman, yaitu melalui tahap: kondensasi data, display data, serta penarikan kesimpulan. ${ }^{7}$ Melalui fenomena yang spesifik, data yang terkumpul setelah dianalisis dilakukan generalisasi guna menghasilkan temuan yang dapat dipaparkan melalui proposisi penelitian. ${ }^{8}$

\section{Pembahasan}

\section{Nilai-Nilai Multikulturalisme Masyarakat Balun}

Nilai-nilai multikulralisme mengandung satu kata kunci penting, yaitu konsep kesederajatan. Konsep ini memiliki implikasi bahwa apapun latar belakang manusianya, dia dipandang sederajat, sehingga perspektif seperti ini akan mudah melahirkan cara

${ }^{6}$ Irving Seidman, [Irving_Seidman]_Interviewing_As_Qualitative_Resea(BookZZ.Org), 2006, https://doi.org/10.1016/0022-2852(61)90347-2.

${ }^{7}$ Matthew B Miles, Michael a Huberman, and Johnny Saldana, "Qualitative Data Analysis: A Methods Sourcebook," SAGE Publications, 2006, https://doi.org/January 11, 2016.

${ }^{8} \&$ Marlene Morrison Christoper Pole., Etnografi for Education, 2003. 
pandang seseorang untuk lebih menghargai, menghormati, dan secara sekaligus menghindarkan diri dari potensi perpecahan. ${ }^{9}$ Kesederajatan berarti adanya persamaan dan penghargaan terhadap keadilan, kesamaan di mata hukum, aspirasi politik, Hak Asasi Manusia (HAM), dan ekspresi kebudayaan. Sehingga dapat dipahami bahwa terminologi multikulturalisme menyimpan sebuah makna tentang kesamaan derajat manusia.

Dalam konteks masyarakat Balun yang beragam, multikulturalisme dipandang sebagai satu paradigma yang tak ternilai harganya, sebagai satu poa pikir dan pola sikap yang harus dikembangkan dan dibina. Oleh karena itu, pendidikan Islam berbasis wawasan multikulturalisme diinternalisasikan secara integral antara keluarga, lembaga pendidikan, dan masyarakat yang bersifat “conditio cine quanon”. Adapun nilai-nilai multikulturalisme yang diinternalisasikan oleh tiga sentra pendidikan Islam, antara lain: toleransi (tasamuh), moderasi bergama (tawasuth), tolong-menolong (ta'awun), dan hamoni sosial (tawazun)

\section{Nilai Toleransi (tasamuh): Mengikis Perbedaan, Menyemai Keberagaman}

Masyarakat Desa Balun memiliki common platform atau semacam kalimat alsawa yang tidak tertulis berupa kesepakatan bersama di antara pemeluk agama atau setiap anggota masyarakat untuk saling menjaga kerukunan kolektif. Untuk itulah, dalam mempertegas keharmonisan sosial ini, sejak tahun 2010 dalam Musrembangdes Balun memproklamirkan dirinya sebagai "Desa Pancasila" sebagai untuk memberikan pesan bahwa masyarakat di sini memiliki spirit persatuan, religiusitas, dan keadaban sosial antara satu dengan yang lain.

Melalui tagline Desa Pancasila, masyarakat Desa Balun memiliki komitmen kuat untuk sama-sama menjunjung tinggi nilai-nilai kebersamaan, keadilan, solidaritas, persatuan, dan keutuhan sosial dengan melibatkan seluruh elemen masyarakat. Dalam konteks ajaran Islam, sikap seperti ini dapat dilihat derivasinya dari pernyataan Nabi bahwa Islam adalah agama yang hanifiyah al-samhah (mudah, lurus, dan lapang). Sebuah hadis yang direkam sangat baik oleh Ibnu Abbas ra, bahwa Rasulullah saw, berkenaan dengan pertanyaan tentang agama yang memiliki karakter semacam apa yang

\footnotetext{
${ }^{9}$ Kuswaya Wihardit, "Pendidikan Multikultural: Suatu Konsep, Pendekatan Dan Solusi," Jurnal
} Pendidikan 11, no. 2 (2010): 96-105, https://doi.org/10.33830/jp.v11i2.561.2010. 
dicintai oleh Allah, Nabi menjawab dengan argumentasi: "al-Hanifiyahal-samhah" (lurusdan yang mudah). ${ }^{10}$

Islam terkandung dalam istilahnya suatu spirit perdamaian, dan tak akan terwujud tanpa adanya rasa saling menghargai dan menghormati atas dasar kemanusiaan. Berdasarkan hal tersebut, maka realitas sosial masyarakat Balun bisa dikategorikan dalam konteks sikap toleransinya berdasar pada: ${ }^{11}$

1) Bahwa perbedaan manusia merupakan kehendak Allah, dengan demikian secara natural manusia mengemban atribut sebagai makhluk berbeda: baik agama, rasial dan strata sosialnya.

2) Dari sisi kemanusiaan, manusia merupakan makhluk yang mulia baik dari segi bangsa, warna kulit dan agamanya.

3) Orang muslim tidak memiliki kewenangan sedikitpun untuk mengintrospeksi saudaranya yang berbeda keyakinan.

4) Salah satu ekspresi keimanan bagi seorang muslim adalah berbuat baik dan adil kepada siapapun tidak memandang latar agamanya.

5) Ajaran Islam tidak melegitimasi orang non-muslim untuk dipaksa memeluk Islam dengan alasan apapun.

6) Islam diturunkan sebagai agama yang kompatibel dengan kemampuan manusia, baik lahir maupun batinnya.

Diskursus toleransi menjadi penting dikedepankan pada masyarakat Balun karena rentan konflik karena fakta sosial masyarakatnya yang berpotensi terjadinya perpecahan. Melalui pengalamannya, warga Desa Balun memiliki kompetensi dalam etika perbedaan pendapat (adab al-ikhtilif) dan dalam "menegosiasikan" isu-isu keagamaan. Salah satu etika berbeda pendapat dalam masyarakat Balun adalah tidak memaksakan keyakinan dengan cara dan bentuk apapun yang dapat menimbulkan kerugian kepada pihak lain. Dalam mengelola perbedaan agama, masyarakat Balun terlihat sangat teguh memegang prinsip untuk tidak memaksanakan agama masingmasing, sebagai ekspresi keyakinan: "bagimu agamamu dan bagiku agamaku". ${ }^{12}$

\footnotetext{
${ }^{10}$ Ihsan Ali-Fauzi, Zainal Abidin Bagir, Irsyad Rafsadi and Ihsan, Kebebasan, Toleransi Dan Terorisme, 2017.

${ }^{11}$ Zainal Abidin Bagir, Robert W. Hefner, and Ihsan Ali-fauzi, Mengelola Keragaman Dan Kebebasan Beragama Di Indonesia: Sejarah, Teori Dan Advokasi [Managing Diversity and Religious Freedom in Indonesia: History, Theory and Advocacy], 2014.

${ }^{12}$ Iqbal, "Pendidikan Multikultural Interreligius: Upaya Menyemai Perdamaian Dalam Heterogenitas Agama Perpsektif Indonesia."
} 
Melihat pluralitas masyarakat Balun, maka untuk menjadikan tatanan sosial tidak monolitik dan rentan dominasi antara yang satu di atas yang lain, maka diperlukan wawasan multikultural melalui sikap moderat dalam soal keyakinan keagamaan. Kenyataan bahwa diversitas rasial dan agama merupakan sesuatu yang terberi (given), maka sikap saling menghormati atas perbedaan sebenarnya juga merupakan bentuk dari penghambaan diri kepada Allah SWT. Dengan demikian, tidak ada satu konsep masyarakat yang tunggal, ia dikonstruksi oleh beragam fenomena dan realitas sosial yang melingkupinya. ${ }^{13}$ Karena itulah maka Islam sangat menekankan pentingnya penghormatan kepada manusia. Hal ini terlihat dari ajarannya yang sangat akomodatif terhadap sisi kemanusiaan: kompleksitas budaya, agama, dan kultur sosial masyarakat. ${ }^{14}$

\section{Nilai Tolong Menolong (ta'awun): Upaya Memperkuat Solidaritas Sosial}

Spirit ta'awun yang ditemukan dalam masyarakat Balun adalah tradisi tolongmenolong, bahu membahu, dan saling berkontribusi atas yang lain saat membutuhkan tanpa memandang status agamanya. Bahkan semenjak kecil, masyarakat Balun terbiasa mendidik anak-anaknya baik di sekolah maupun dalam keluarga untuk saling membantu dengan teman sebayanya. Seperti halnya ketika kesulitan belajar bahasa Arab bagi nonmuslim, menjenguk teman beda agama yang sakit, serta tak segan membantu tetangga yang mengalami kesusahan. ${ }^{15}$

Selain itu, setiap manusia yang memiliki kebutuhan dan kepentingan dalam hidupnya, tidak serta merta -dalam konteks warga Balun- mengorbankan kepentingan kelompok agama lain. Hal ini didasarkan bagaimana mereka saling gotong royong mengkondisikan lingkungan sekitar agar dapat menyelenggarakan ritual ibadah agama secara khidmat, baik Nyepi, Idul Fitri, dan Natal. Melalui nilai ta'awun yang telah menjadi budaya pada masyarakat Balun, mereka memiliki kesempatan atau potensi yang sangat besar untuk mewujudkan cita dan harapannya. Dalam nilai ini dapat dipahami bahwa warga memiliki kesadaran untuk mendengar lebih jauh perasaan dan keyakinan orang lain, melihat lebih jeli atas kebutuhan orang lain atas dirinya dan kesediaan menggerakkan tangan untuk saling menjaga agar sensifitas agama tidak

\footnotetext{
${ }^{13}$ Zainal Abidin Bagir and AA GN Ari Dwipayana Mustaghfiroh Rahayu Trisno Sutanto Farid Wajidi, Pluralisme Kewargaan (Bandung: Mizan, 2011).

${ }^{14}$ Eka Prasetiawati, "Menanamkan Islam Moderat Upaya Menanggulangi Radikalisme Di Indonesia," Fikri 2, no. 2 (2017): 523-70, http://library1.nida.ac.th/termpaper6/sd/2554/19755.pdf.

${ }^{15}$ Eni Puji Utami, Kunarti, and Dkk Meike Lusye Karolus, Praktik Pengelolaan Keragaman Di Indonesia, 2018.
} 
mengorbankan kedaulatan sosial yang dapat mengancam keutuhan sebagai satu kesatuan masyarakat.

Bangunan komunikasi profetik yang mengedepankan semangat persatuaan dan kebersamaan merupakan bentuk yang paling ekspresif dari ketakwaan kepada Tuhan Yang Maha Esa. Dalam realitas masyarakat yang multikultural, sebagaimana yang terjadi pada masyarakat Balun, artikulasi keimanan diwujudkan pada sikap saling tenggang rasa, saling mengunjungi jika ada saudara dan tetangga yang sedang sakit atau mendapatkan musibah tanpa memerhatikan background keagamannya. ${ }^{16}$

Dengan demikian, konsep kebaikan dalam pendidikan Islam adalah timbulnya sikap saling peduli, sehingga responsif terhadap keadaan tetangga atau keluarga saat tertimpa cobaan dengan pertimbangan utama adalah sama-sama manusia ciptaan Tuhan. Ekspresi keimanan ini merupakan perwujudan dari ayat al-Quran yang menyatakan bahwa Allah benar-benar memuliakan anak adam (baca: manusia) tanpa embel-embel atribut kultural apapun. Sebaliknya, bahwa kezaliman apapun bentuknya tidak ditoleransi sedikitpun di dalam ajaran Islam.

Pesan komunikasi profetik ini sangatlah jelas bahwa berkonspirasi dalam kejahatan sangat dilarang. Konsesus masyarakat untuk melahirkan perpecahan, sejurus kemudian dalam hal ini menjadi perilaku yang sangat dilarang. Maka tidaklah mungkin seseorang dengan akal, hati dan keimanan yang benar, sehat dan lurus akan melakukan pengkhianatan atas dirinya sendiri dengan tunduk pada isu-isu perpecahan. ${ }^{17}$

Hal penting yang perlu diketengahkan di sini adalah kegiatan gotong royong antar umat beragama yang telah menjadi "kebudayaan wajib". Kearifan yang telah menjadi kekayaan lokal masyarakat Balun merupakan kristalisasi dari semangat saling tolong-menolong dan guyub rukun sehingga tersemai kondisi sosial masyarakat yang aman. Kenyataan ini berarti semangat tolong-menolong masyarakat Balun menyimpan implikasi sosial dalam membentuk sebuah kultur atau peradaban masyarakat yang harmonis. Dalam tradisi kerja bakti misalnya, selain tidak mendapatkan upah, warga secara sukarela membersihkan daerahnya dengan tanpa mempertimbangkan ini daerah muslim atau non-muslim. ${ }^{18}$

\footnotetext{
${ }^{16}$ Sinta Paramita and Wulan Purnama Sari, "Intercultural Communication to Preserve Harmony Between Religious Group in Jaton Village Minahasa (Komunikasi Lintas Budaya Dalam Menjaga Kerukunan Antara Umat Beragama Di Kampung Jaton Minahasa)," Journal Pekommas 1, no. 2 (2016): 153, https://doi.org/10.30818/jpkm.2016.2010205.

${ }^{17}$ Prasetiawati, "Menanamkan Islam Moderat Upaya Menanggulangi Radikalisme Di Indonesia."

${ }^{18}$ Ismail Fahmi Arrauf Nasution, "Minoritas Dan Politik Perukunan (FKUB, Ideologi Toleransi Dan Relasi Muslim-Kristen Aceh Tamiang)," Substantia 19, no. April (2017): 53-74.
} 
Teologi ta'awun masyarakat Balun jika dikategorikan sebagaimana konsep Koentjaraningrat, dapat dibedakan ke dalam dua macam, yakni tolong-menolong yang bersifat spontan dan bersifat norma sosial. Untuk sifat yang didasarkan pada norma sosial adalah, masyarakat Balun jika saling gotong-royong tanpa disuruh jika terdapat tetangga atau saudara yang menyelenggarakan hajat. Sedangkan tolong-menolong secara spontan dilakukan tanpa permintaan dan tanpa pamrih untuk hal-hal yang sifatnya tiba-tiba seperti kematian dan bencana lain. Hal ini terlihat ketika anggota masyarakat Balun saat menyelenggarakan acara sunatan dan mantenan, mereka saling membantu atau "rewang", terutama tenaga kerja, seperti: memasang tenda, memasak, menerima tamu, juru ladi atau pelayan, dan sebagainya. Begitu juga ketika terdapat anggota masyarakat sedang mengalami musibah kematian, mereka saling membantu secara spontan dan tanpa pamrih.

\section{Nilai Harmoni Sosial (tawazun): Memperkuat Kerukunan Multi Religi}

Berkaitan dengan penelitian ini ada terminologi yang digunakan dan perlu dikonsepsualisasikan terlebih dahulu agar dapat dimengerti maksud dan batasannya, yaitu masyarakat harmoni. Harmoni adalah "suatu kondisi selaras, teratur, tenteram, dan seimbang." Dengan demikian, dalam konteks penelitian pada masyarakat Balun ini dapat dipahami sebagai masyarakat yang terdiri atas sekelompok manusia yang hidup bersama dengan adanya ikatan sosial-keagamaan yang diliputi suasana keselarasan, keteraturan, ketenteraman,,dan keseimbangan.

Paradigma di atas menggambarkan bahwa masyarakat Balun yang mendapat predikat sebagai desa Pancasila terbentuk sebagai konsekuensi dari adanya kerjasama timbal-balik antara lembaga pendidikan, keluarga (household), dan masyarakat sebagai pilar utama sentra kehidupan harmonis (ta'awun). Sehingga kondisi harmonis yang bisa dikatakan tercapai saat ini merupakan kondisi ideal yang diperoleh ketika masingmasing anggota masyarakat, baik sebagai pemeluk agama, sebagai guru, sebagai anggota keluarga sekaligus anggota masyarakat menjalani peran dan fungsinya secara benar dengan didasarkan pada nilai-nilai kemanusiaan, kemajemukan dan persaudaraan (ukhuwah). ${ }^{19}$

Dalam tradisi akademik, padanan masyarakat harmoni mempunyai banyak istilah. Dalam Islam, istilah yang digunakan adalah masayarakat madani (tamadun).

\footnotetext{
${ }^{19}$ Miftahuddin, "Islam Moderat Konteks Indonesia Dalam Pespektif Historis,” Mozaik V, no. 1 (2010):
} 41-54. 
Merujuk pada konsepnya Madjid bahwa masayarakat yang madani memberikan konstribusi sosial-psikologis berupa ketenangan batin serta kebahagiaan dan kesejahteraan yang hakiki bagi segenap anggota masyarakat, tanpa kekerasan, ancaman, intimidasi, dan kesalingcurigaan. Sebagai masyarakat yang harmonis, Desa Balun dalam riset ini bisa dicirikan sebagai masyarakat yang lahiriah dan batiniahnya, karena dengan secara bebas menjalankan ritual keagamaan dengan penghormatan sekaligus penghargaan dari pemeluk agama lain. ${ }^{20}$ Ritual-ritual keagamaan masyarakat Balun, seperti upacara Nyepi, Kebaktian, dan salat tarawih mendapatkan penghargaan yang luar biasa dari sesama anggota masyarakat. Pemeluk agama didorong untuk menjalankan ritus keagamaannya dengan khidmat dan khusyuk', sehingga pemeluk agama lain rela untuk "mengorbankan ego keagamaannya" agar tetangganya yang menjalankan ritual agamanya bisa menunaikannya secara khidmat.

Melihat kuatnya komitmen solidaritas masyarakat Balun, baik diartikulasikan dalam lembaga pendidikan, keluarga, dan masyarakat, agaknya tidak berlebihan jika mengklaim para anggota masyarakat di sini telah secara baik menjalankan fungsi dan perannya sebagai anggota masyarakat sekaligus sebagai pemeluk agama yang baik. Dengan tidak segan menjenguk tetangga yang sakit, saling berkunjung saat perayaan hari raya agama-agama sekaligus tak alergi menghadiri undangan hajatan walau berbeda agama, menunjukkan tingkat ukhuwah insaniyah warga Balun yang telah matang dan mapan. Singkatnya, fungsionalisme dalam masyarakat ini mempunyai hubungan satu sama lainnya yang menyatu dalam satu dimensi kekeluargaan. Setiap bagian dari anggota keluarga adalah fungsional bagi lainnya. ${ }^{21}$

Selain itu, adaptasi Islam pada kebudayaan dan konstruksi agama-agama pada masayarakat Balun membuktikan bahwa para pemeluk agama Islam memandang pluralitas sebagai suatu keniscayaan. Dengan kemampuan adaptasi masyarakat berinteraksi dengan lingkungan dan alam sosialnya dengan fleksibel. Lalu memiliki kecakapan untuk mengatur dan menyusun tujuan-tujuan masa depan dan membuat keputusan yang sesuai dengan itu. Integration atau harmonisasi dalam struktur sosial masyarakat merupakan general agreement yang dibangun di atas koridor kearifan lokal masyarakat Balun, semisal: tradisi jogo regol, halal bi halal, dan saling menjaga saat

\footnotetext{
${ }^{20}$ Ahmad Rizky Mardhatillah Umar, "A Genealogy of Moderate Islam: Governmentality and Discourses of Islam in Indonesia's Foreign Policy,” Studia Islamika 23, no. 3 (December 30, 2016): 399-433, https://doi.org/10.15408/sdi.v23i3.3157.

${ }^{21}$ Abdurrahman Wahid, Islam Kosmopolitan: Nilai-Nilai Indonesia Dan Transformasi Kebudayaan (jakarta: The Wahid Institute, 2007).
} 
ada perayaan agama merupakan pengejawantahan nilai-nilai atau norma pada masyarakat ditetapkan.

\section{Nilai Moderasi Beragama (tasawuth): Beragama dengan Bahasa Kemanusiaan}

Pada dasarnya, ketika dilahirkan, manusia sudah membawa naluri untuk beragama, dalam arti mengenal Tuhan,meski kadarnya sangat kecil. Rudolf Ottodan St. Agustinus menyatakan: “...they are born with inner capacity of sensing God and cannot help themselves." Maka dalam perspektif psikologi agama, manusia disebut homo religious. Kondisi seperti itu dalam Islam disebut fitrah, disebutkan dalam al-Qur'an Surat al-Rum: 30, yang artinya: "Maka hadapkanlahwajahmu dengan lurus kepada agama (Allah);(tetaplah atas) fitrah Allah yang telah menciptakan manusia menurutfitrah itu. Tidak ada perubahan pada fitrah Allah. (Itulah)agama yanglurus; tetapi kebanyakan manusia tidak mengetahui." (Q. S. al-Rum,30: 30). Selain itu, Rasulullah pun mempertegas lagi dalam hadis yang artinya: "Tidaklah seorang anak dilahirkan ke dunia kecuali dalam keadaan suci. Maka kedua orang tuanyalah yang menjadikannya (memeluk) Yahudi, Nasrani atau Majusi.” (Muslim, 1377H: 216).

Adanya naluri beragama tersebut dapat ditelusuri secara psikologis dengan mencermati fenomena adanya tradisi pembacaan do'a bagi orang yang meninggal, atau mendoakan orang yang tengah sakit. Kesadaran sebagai makhluk beragama ini sangat lekat dalam kehidupan masyarakat Balun yang multi agama. Tentunya, berdo'a sebagai suatu aktifitas ritual tersebut ditujukan kepada Yang Menguasai Hidup, walau dengan "imagi dan standar" mengenai konsep Tuhan yang berbeda. ${ }^{22}$

Bersikap moderat (tawasuth) yaitu berupaya berada di jalur tengah telah menjadi bagian dari platform kemasyarakatan warga Balun. Mereka tak segan mempersilakan, misalnya siswa nonmuslim untuk tidak mengikuti ritual keagamaan siswa muslim saat di sekolah, pun juga dalam soal mata pelajaran agama, para siswa berkumpul namun dipisahkan sesuai dengan pembelajaran agamanya masing-masing. ${ }^{23}$ Cara seperti ini mencirikan sikap moderasi bergama yang dapat diidentifikasi melalui sikap: a) Tawasuth dan i'tidal, menjunjung tinggi keharusan berlaku adil di tengah kehidupan

\footnotetext{
${ }^{22}$ A.Hermawan, "NILAI MODERASI ISLAM DAN INTERNALISASINYA DI SEKOLAH M. A. Hermawan Institut Agama Islam Negeri Purwokerto," Insania 25, no. 1 (2020): 31-43.

${ }^{23}$ Winarto Eka Wahyudi, "Radikalisme Dalam Bahan Ajar Dan ANalisa Wacana Kritis Perspektif Van Dijk Terhadap Materi PAI Tingkat SMA," Jalie: Journal of Applied Linguistics and Islamic Education 1, no. 1 (2017): 9-15.
} 
bergama; b) toleransi terhadap perbedaan; c) menganjurkan kebaikan kolektif dan menghindari sentimen-sentimen keagamaan yang dapat menyulut perpecahan.

Bagi masyarakat Balun yang menampilkan ciri beragama yang moderat, misi utama dalam beragama adalah menghadirkan substansi nilai-nilai agama di masyarakat demi terwujudnya kedamaian dan ketenteraman bersama. Misi ini sesuai dengan visi Islam yang merujuk pada fungsinya sebagai agama rahmatan lil 'alamin. Sejurus kemudian, sikap moderat dalam beragama menjadi antitesis dari sikap keagamaan yang cenderung fundamental atau radikal, yang dalam tradisi akademik lazim disebut sebagai extreme religious (al-tatharruf al-dini) yang berarti lawan moderatisme (al-tawassuth wa al-I'tidal). ${ }^{24}$ Sikap berupaya untuk menghargai keberagaman bersama menegasikan suatu kelompok keagamaan yang cenderung kaku di dalam menafsirkan doktrin agama dan lebih memilih jalan kekerasan di dalam mencapai tujuan. Pengertian ini dalam perkembangannya sering diposisikan sebagai kelompok oposisi dalam suatu tatanan masyarakat yang dianggap tidak islami, untuk tidak menyebunya kafir.

Salah satu kearifan lokal masyarakat Balun adalah penghargaan dan penghormatan terhadap perayaan keagamaan, baik Islam, Kristen, dan Hindu. Mereka tak segan bahu membahu untuk melancarkan kegiatan keagamaan agar berjalan dengan khidmat. Namun bantuan itu yang bersifat, sosial kemasyarakatan, bukan ritual keagamaan. Hal-hal semacam ini, tentu akan berimplikasi secara diametral dengan ciri sikap yang melekat pada kaum ektrimis yang cenderung alergi terhadap perbedaan, sikap dan pandangan yang radikal, militan, berpikiran sempit (narrow minded), semangat beragaman terlalu berlebihan namun miskin ilmu (ultrazealous), atau cenderung ingin mencapai tujuan dengan menggunakan cara-cara kekerasan. Sehingga bisa dipahami, sikap keagamaan yang moderat pada masayarakat Balun merupakan upaya untuk meminimalisasi paham keagamaan yang ekstrim. Karena jika paham tersebut telah mengkooptasi harmoni sosial masyarakat, bukan tidak mungkin, akan menimbulkan kesalahpahaman (misleading) yang memicu terjadinya violence, karena cenderung lebih menyudutkan satu pihak dan menguntungkan pihak lain.

\footnotetext{
${ }^{24}$ Winarto Eka Wahyudi, "Ethnic Minority Muslim Social Pedagogy (Counter-Radicalism of Chinese Muslims through Islamic Education)," Edukasia : Jurnal Penelitian Pendidikan Islam 15, no. 1 (2020): 119, https://doi.org/10.21043/edukasia.v15i1.7360.
} 


\section{Internalisasi Nilai-Nilai Pendidikan Islam Multikultural}

Kearifan lokal yang menjadi aset integrasi masyarakat harmonis desa Balun bisa dikatakan sebagai suatu sintesis budaya yang diciptakan oleh aktor-aktor lokal melalui proses yang berulang-ulang (continum) yakni melalui internalisasi dan interpretasi ajaran agama dan budaya yang kemudian disosialisasikan dalam bentuk norma-norma serta dijadikan pedoman dalam kehidupan sehari-hari masyarakat Balun. Dalam konteks kajian ini, meminjam gagasan James Banks tentang pendidikan Multikultural, maka nilai-nilai yang terkandung di dalamnya yang berisi "gagasan" tentang keadilan, toleransi, dan moderatisme dapat dilakukan dengan mengintegrasikan nilai multikultural ke dalam norma sosial atau perencanaan pembelajaran di lembaga yang berada di wilayah tersebut, tentu saja dalam hal ini SDN 1 Balun sebagai subjek penelitiannya. ${ }^{25}$

Sebagaimana kategorisasi yang telah dilakukan oleh Banks,maka dapat dilihat bahwa penanaman nilai multikultural masyarakat Balun berjalan di atas dua tahapan, yaitu: tahap penambahan (additive level) dan tahap perubahan (transformative level) ${ }^{26}$ Dalam tahap penambahan (additive level), baik di lingkungan keluarga, sekolah, dan masyarakat sejak dini menyisipkan wawasan-wawasan moralitas kepada anaknya dalam membangun toleransi kepada teman dan saudaranya yang berbeda agama, begitupun dengan masyarakat yang sering melibatkan semua unsur pemeluk agama dalam memperingati hari besar agama dan hari besar nasional, untuk memupuk semangat persaudaraan, kerukunan dan kesatuan antar warga multi agama.

Selanjutkan dalam tahap transformatif, menurut Banks, masyarakat dipandang mampu melihat konsep-konsep dari sejumlah perspektif budaya, etnik dan agama secara kritis. Dalam level ini melalui orang tua, tokoh agama, dan tokoh masyarakat serta guru-guru SD, guru ngaji desa Balun, secara serempak melakukan indoktrinasi perspektif-perspektif, kerangka-kerangka referensi dan gagasan-gagasan yang memperluas pemahaman warga masyarakat tentang sebuah ide, pandangan moral tentang tata kehidupan yang harmonis melalui sikap-sikap yang toleran dan demokratis.

Proses internalisasi nilai pendidikan Islam multikultural yang terlihat pada masyarakat Balun dilakukan melalui beberapa aspek tahapan, yakni: transformasi nilai, transaksi nilai, dan tahap trans-internalisasi nilai. Dalam proses internalisasi yang

\footnotetext{
${ }^{25}$ JA Banks, An Introduction to Multicultural Education., 1994, http://www.eric.ed.gov/ERICWebPortal/recordDetail?accno=ED372129.

${ }^{26}$ James A. Bank, "Multicultural Education: Historical Development, Dimmension and Practice," American Educational Research Assosiation 19 (1993).
} 
dikaitkan dengan pembinaan perilaku hidup rukun, harmonis dan toleran berlangsung melalui antara lain: ${ }^{27}$

a. Tahap transformasi nilai. Pada tahap ini terjadi upaya yang dilakukan oleh orang tua, tokoh agama, dan masyarakat serta guru untuk menyadar-pahamkan tentang pentingnya hidup rukun dan harmonis. Transformasi nilai, dengan demikian, hanya berjalan melalui komunikasi verbal, melalui arahan orang tua terhadap anak, atau tokoh masyarakat kepada warga desa, serta pengajaran dan nasehat guru kepada murid-muridnya yang bersifat mentransmisikan nilai-nilai etik kepada orang lain.

b. Tahap transaksi nilai. Proses penginternalisasian nilai melalui komunikasi dua arah antara dua orang atau lebih dalam satu komunitas masyarakat secara timbal balik, sehingga terjadi proses interaksi sosial. Dengan adanya transaksi nilai ini, tokoh masyarakat, guru, dan tokoh agama dapat memengaruhi nilai orang lain melalui contoh nilai yang dijalankannya (modeling) melalui perilaku-perilaku nyata dalam interaksi sosial di tengah keberagaman agama.

c. Tahap trans-internalisasi. Proses penginternalisasian nilai-nilai pendidikan Islam multikultural melalui proses yang bukan hanya komunikasi verbal tetapi juga disertai komunikasi kepribadian yang ditampilkan melalui keteladanan, pengkondisian serta melalui proses pembiasaan atau pembudayaan (inkulturasi) untuk berperilaku sesuai dengan nilai yang diharapkan. ${ }^{28}$

Melalui kerangka paradigmatik di atas, dapat diketahui bahwa Desa Pancasila yang menjadi tagline masyarakat Desa Balun mencerminkan pola pikir dan pola sikap keagamaan masyarakat Balun yang toleran dan demokratis, serta memilili cara pandang yang moderat. Nilai-nilai multikulturalisme di atas tidak berjalan secara tiba-tiba dan bersifat taken for granted, namun dilakukan melalui sebuah proses atau upaya yang dialektis-integral antar berbagai pihak, baik dari masyarakat, keluarga, dan lingkungan pendidikan yang secara serentak turut melakukan proses internalisasi nilai-nilai sosialkeagamaan yang kompatibel dengan realitas masyarakat yang plural. ${ }^{29}$

\footnotetext{
${ }^{27}$ Kuswaya Wihardit, "Pendidikan Multikultural: Suatu Konsep, Pendekatan Dan Solusi."

${ }^{28}$ Muhaimin, Setrategi Belajar Mengajar, (Surabaya: Citra Media, 1996), hlm. 153., liha juga Kama Abdul Hakam dan Encep Syarief Nurdin, Metode Internalisasi Nilai-nilai untuk Memodifikasi Perilaku Berkarakter, (Bandung: CV. Maulana Media Grafika, 2016), hlm. 14.

${ }^{29}$ Carl A. Grant; Joy L. Lei, "Global Construction of Multicaultural Education: Theorities and Realities," in The British Journal of Psychiatry, ed. Carl A. Grant; Joy L Lei, vol. 111, 1965, 1009-10, https://doi.org/10.1192/bjp.111.479.1009-a.
} 


\section{Internalisasi Nilai Multikulturalisme..., Ahmad Hanif F, Maskuri, Hasan Busri}

\section{Penutup}

Realiatas masyarakat yang plural sebagaimana paparan dalam kajian ini, menjadi pisau bermata dua. Di satu sisi menjadikan peradaban masyarakat lebih kaya dengan berbagai ornamen khazanah kebudayaan masing-masing, namun di sisi lain, jika tidak pandai mengelola akan menjadi bom waktu yang setiap saat kita harus bersiap menelan pil pahit akibat gagal mengelola keragaman, sehingga konflik horisontal tak bisa terelakkan lagi. Mengaca dari religiuos experience masyarakat Balun, dengan komposisi pemeluk agama beragama namun berhasil mengelolanya dengan baik, ditemukan bahwa kondisi masyarkat yang harmonis membutuhkan kontribusi dan peran multi pihak.

Dalam kajian tentang internalisasi nilai multikulturalisme ini, didapatkan temuan antara lain: 1) multikulturalisme berhasil diinternalisasikan melalui berbagai pihak secara integratif-dialektif, baik di lingkungan keluarga, sekolah, dan masyarakat, 2) nilai-nilai multikultural yang diinternalisasikan meliputi sikap toleransi (tasamuh), harmoni sosial (tawazun), saling tolong-menolong (ta'awun), dan moderasi dalam beragama (tawasuth), 3) proses internalisasi nilai-nilai multikultural dilakukan melalui kontribusi tri relasi pendidikan yang mengambil dua pola baik secara additive maupun transformatif level. Selain itu, penelitian ini juga menemukan bahwa internalisasi nilai multikultural berjalan melalui tahapan transformasi nilai, transaksi nilai, dan transinternalisasi nilai yang diwujudkan melalui pengajaran dan pembudayaan masyarakat dengan sikap toleran (tasamuh) sekaligus moderat (tawasuth).

\section{Referensi}

A.Hermawan. "Nilai moderasi islam dan internalisasinya di sekolah,." Insania 25, no. 1 (2020): 31-43.

Bagir, Zainal Abidin, Robert W. Hefner, and Ihsan Ali-fauzi. Mengelola Keragaman Dan Kebebasan Beragama Di Indonesia: Sejarah, Teori Dan Advokasi [Managing Diversity and Religious Freedom in Indonesia: History, Theory and Advocacy], 2014.

Bagir, Zainal Abidin, and AA GN Ari Dwipayana Mustaghfiroh Rahayu Trisno Sutanto Farid Wajidi. Pluralisme Kewargaan. Bandung: Mizan, 2011.

Banawiratma, J.B, Zainal Abidin Bagir, Fatimah Husein, Suhadi Cholil, Novita Rakhmawati, Ali Amin, Budi Asyhari, and Mega Hidayati. Dialog Antarumat Beragama: Gagasan Dan Praktik Di Indonesia. Jakarta: PT Mizan Publika, 2010.

Bank, James A. "Multicultural Education: Historical Development, Dimmension and Practice.” American Educational Research Assosiation 19 (1993).

Banks, JA. An Introduction to Multicultural Education., 1994. 
http://www.eric.ed.gov/ERICWebPortal/recordDetail?accno=ED372129.

Christoper Pole., \& Marlene Morrison. Etnografi for Education, 2003.

Iqbal, Mahathir Muhammad. "Pendidikan Multikultural Interreligius: Upaya Menyemai Perdamaian Dalam Heterogenitas Agama Perpsektif Indonesia." Sosio Didaktika 1, no. 1 (2014): 89-97.

Kamal, Aulia. "Spiritual-Humanisme Hasan Askari Dan Dialog Interreligi Di Indonesia." Studia Sosia Religia 2, no. 2 (2019).

Kuswaya Wihardit. "Pendidikan Multikultural: Suatu Konsep, Pendekatan Dan Solusi." Jurnal Pendidikan 11, no. 2 (2010): 96-105. https://doi.org/10.33830/jp.v11i2.561.2010.

Lei, Carl A. Grant; Joy L. "Global Construction of Multicaultural Education: Theorities and Realities." In The British Journal of Psychiatry, edited by Carl A. Grant; Joy L Lei, 111:1009-10, 1965. https://doi.org/10.1192/bjp.111.479.1009-a.

Miftahuddin. "Islam Moderat Konteks Indonesia Dalam Pespektif Historis.” Mozaik V, no. 1 (2010): 41-54.

Miles, Matthew B, Michael a Huberman, and Johnny Saldana. "Qualitative Data Analysis: A Methods Sourcebook." SAGE Publications, 2006. https://doi.org/January 11, 2016.

Muryana. "Dialog Interreligius-Kultural Dan Civil Religion (Studi Atas Paguyuban Ngesti Tunggal (Pangestu).” ESENSIA XIV, no. 2 (2013): 203-2016.

Nasution, Ismail Fahmi Arrauf. "Minoritas Dan Politik Perukunan (FKUB, Ideologi Toleransi Dan Relasi Muslim-Kristen Aceh Tamiang)." Substantia 19, no. April (2017): 53-74.

Paramita, Sinta, and Wulan Purnama Sari. "Intercultural Communication to Preserve Harmony Between Religious Group in Jaton Village Minahasa (Komunikasi Lintas Budaya Dalam Menjaga Kerukunan Antara Umat Beragama Di Kampung Jaton Minahasa).” Journal Pekommas 1, no. 2 (2016): 153. https://doi.org/10.30818/jpkm.2016.2010205.

Prasetiawati, Eka. "Menanamkan Islam Moderat Upaya Menanggulangi Radikalisme Di Indonesia." Fikri 2, no. 2 (2017): $523-70$. http://library1.nida.ac.th/termpaper6/sd/2554/19755.pdf.

Rafsadi, Ihsan Ali-Fauzi, Zainal Abidin Bagir, Irsyad, and Ihsan. Kebebasan, Toleransi Dan Terorisme, 2017.

Seidman, Irving. [Irving_Seidman]_Interviewing_As_Qualitative_Resea(BookZZ.Org), 2006. https://doi.org/10.1016/0022-2852(61)90347-2.

Umar, Ahmad Rizky Mardhatillah. "A Genealogy of Moderate Islam: Governmentality and Discourses of Islam in Indonesia's Foreign Policy." Studia Islamika 23, no. 3 (December 30, 2016): 399-433. https://doi.org/10.15408/sdi.v23i3.3157.

Utami, Eni Puji, Kunarti, and Dkk Meike Lusye Karolus. Praktik Pengelolaan Keragaman Di Indonesia, 2018.

Wahid, Abdurrahman. Islam Kosmopolitan: Nilai-Nilai Indonesia Dan Transformasi Kebudayaan. jakarta: The Wahid Institute, 2007.

Wahyudi, Winarto Eka. "Ethnic Minority Muslim Social Pedagogy (Counter- 
Radicalism of Chinese Muslims through Islamic Education)." Edukasia: Jurnal Penelitian Pendidikan Islam 15, no. 1 (2020): 119. https://doi.org/10.21043/edukasia.v15i1.7360.

. "Radikalisme Dalam Bahan Ajar Dan ANalisa Wacana Kritis Perspektif Van Dijk Terhadap Materi PAI Tingkat SMA." Jalie: Journal of Applied Linguistics and Islamic Education 1, no. 1 (2017): 9-15. 